J. Lake Sci.(湖泊科学), 2017, 29(4): 811-818

DOI 10. 18307/2017. 0404

(C) 2017 by Journal of Lake Sciences

\title{
结冰对乌梁素海水体富营养化的影响”
}

\author{
张 岩 ${ }^{1}$, 李畅游 ${ }^{2}$, 高 宁 $^{1}$, 史小红 ${ }^{2}$, 乔玲敏 ${ }^{1}$ \\ ( 1 : 烟台大学土木工程学院, 烟台 264005) \\ (2: 内蒙古农业大学水利与土木建筑工程学院, 呼和浩特 010018)
}

\begin{abstract}
摘 要: 为研究结冰对湖泊富营养化状态的影响, 以内蒙古乌梁素海为研究对象, 用 “注射器”式采水器和冰钻分别采集 水样和冰样, 并测定总氮、总磷、 $\mathrm{COD}_{\mathrm{Cr}}$ 、叶绿素 $\mathrm{a}$ 浓度、冰厚、水深和透明度等指标, 运用分形理论评价模型对湖泊结冰 前、后的富营养化等级进行综合评价. 结果表明: 乌梁素海湖泊结冰厚度与水深存在较好的负相关性, 其相关系数为 0.54 ; 湖泊结冰后, 水体的富营养化等级由富营养变为重富营养, 表明结冰过程中, 氮、磷等营养元素被排斥至冰下水体, 即结冰过程对湖泊水体中的营养元素具有浓缩效应, 导致冰下环境质量恶化, 并促进营养元素向沉积物转移; 但也可以 利用该浓缩效应, 从湖泊冰封期富营养化污染的特殊性人手, 运用底泥疏浚和冰体-水体分离等工程技术手段, 实现湖泊 富营养化污染的治理.
\end{abstract}

关键词: 结冰;富营养化;分形理论;乌梁素海

\section{Effect of freezing on eutrophication in Lake Ulansuhai}

ZHANG Yan ${ }^{1}$, LI Changyou ${ }^{2}$, GAO Ning ${ }^{1}$, SHI Xiaohong ${ }^{2} \&$ QIAO Lingmin ${ }^{1}$

(1: Civil Engineering College, Yantai University, Yantai 264005, P.R. China)

(2: Water Conservancy and Civil Engineering College, Inner Mongolia Agricultural University, Huhhot 010018, P.R.China)

\begin{abstract}
In order to study the effect of freezing on lake eutrophication, Lake Ulansuhai, located in Inner Mongolia, was selected as the study object. The ice and water sample were collected respectively by syringe water sampler and ice drill. The total nitrogen, total phosphorus, $\mathrm{COD}_{\mathrm{Cr}}$, chlorophyll-a, ice thickness, water depth and transparency of each sample were measured. The eutrophic state of Lake Ulansuhai before and after freezing were assessed by the means of fractal theory. The results showed that there was a good negative correlation between water depth and ice thickness in Lake Ulansuhai, and the correlation coefficient was 0.54. The trophic state of water before freezing was eutrophication, and changed to heavy eutrophication after freezing. The results also showed that nutrient elements such as nitrogen and phosphorus were ejected to water during the period of ice growth, that is to say, the process of freezing had a good concentrating effect on pollutants in water. This effect also can make pollutants migrate from water to sediment during ice growth process, which made the quality of under-ice environment deteriorate. While the concentrating effect can provide theoretical basis and data support for the sediment dredging and ice-water separating during ice-on period.
\end{abstract}

Keywords: Freezing; eutrophication; fractal theory; Lake Ulansuhai

湖泊是重要的淡水资源之一, 我国湖泊数量众多、分布广泛, 但由于水体中氮、磷等浓度增加, 导致湖泊 富营养化不断加重. 据统计, 我国有 $85.4 \%$ 的湖泊超过了富营养化标准, 达到重富营养化程度的湖泊达 $40.1 \%{ }^{[1]}$. 为此,众多学者在湖泊富营养化方面开展了大量的研究并取得了大量的成果,但这些研究大都基 于湖泊的非冰封条件下进行的, 而对湖泊冰封条件下湖泊的富营养化特征却少见报道. 国内仅有的几篇文 献主要研究了氮、磷等在冰-水体系的分配关系和其在冰生长期的迁移过程 ${ }^{[2-5]}$, 而未曾耦合结冰过程对总 氮 $(\mathrm{TN})$ 、总磷 $(\mathrm{TP}) 、 \mathrm{COD}_{\mathrm{Cr}}$ 、叶绿素 $\mathrm{a}(\mathrm{Chl} . \mathrm{a})$ 和透明度 $(\mathrm{SD})$ 等的影响, 阐明结冰过程对湖泊富营养化状态的

* 山东省优秀中青年科学家科研奖励基金项目 (BS2014HZ021) 和国家自然科学基金项目 $(51609207,51339002$ )联合 资助. 2016-07-22 收稿; 2016-10-18 收修改稿. 张岩(1984 ), 男,博士, 副教授; E-mail: zhangyan-992@163. com. 
影响. 而国外尚未见湖泊冰封期富营养化方面的报道. 但湖泊冰封期, 由于冰层的存在几乎切断了大气-水 体物质交换和削弱了其间的能量交换, 改变了整个体系的透光性和热传导性 ${ }^{[6]}$, 水中存在的微生物数量很 少, 且微生物的生物降解能力极低; 湖水中污染物失去迁移和光解作用, 并使自然曝气形成的复氧过程几乎 停止, 并且光合作用微弱, 溶解氧浓度处于极低值, 氧化还原电位降低, 水体的自净能力大大减弱. 因此, 结 冰必将对湖泊的富营养化状态产生影响.

\section{1 材料与方法}

\section{1 研究区概况}

乌梁素海 $\left(40^{\circ} 36^{\prime} \sim 41^{\circ} 03^{\prime} \mathrm{N}, 108^{\circ} 43^{\prime} \sim 108^{\circ} 57^{\prime} \mathrm{E}\right.$ ) 位于内蒙古自治区巴彦淖尔市境内, 水面面积为 283 $\mathrm{km}^{2}$, 水深 1.4 3.1 m, 是国家八大淡水湖之一. 该湖泊主要承纳河套灌区的农田退水及流域内部分工业废水 和生活污水, 湖泊富营养化严重. 乌梁素海流域属北温带大陆性干旱/半干旱气候, 多年平均气温为 5.6 $7.4^{\circ} \mathrm{C}$, 一般从每年 11 月开始结冰, 翌年 3 月末开始融化, 冰封期约 $4 \sim 5$ 个月, 冰层的最大厚度可达 $0.70 \mathrm{~m}$. 2012 实验年度内乌梁素海湖泊的结冰期为 11 月 25 日至次年 2 月 18 日. 冬季冰盖形成后, 湖泊接近静水 体, 环流作用微弱, 与外界水体的交换近乎停止.

\section{2 样品采集}

根据我国水环境及湖泊调查规范, 考虑乌梁素海的水文及水环境特征, 设置采样点 (图 1), 并于 2012 年 1 月在每个采样点上分别采集冰样和水样: 用冰钻采集 6 根冰芯样品, 用电子天平称量每根冰芯样品的重量 并将其放在切割板上, 用冰锯从上至下每 $10 \mathrm{~cm}$ 切割一段冰柱, 并将其放在塑料瓶中, 在室温下自然融化后 进行监测; 用 “注射器”式采水器通过冰孔各抽取冰-水界面、冰下 $30 \mathrm{~cm}$ 和水-沉积物界面的水各 $1000 \mathrm{ml}$, 将上述 3 个位置的水样均匀混合后进行监测.
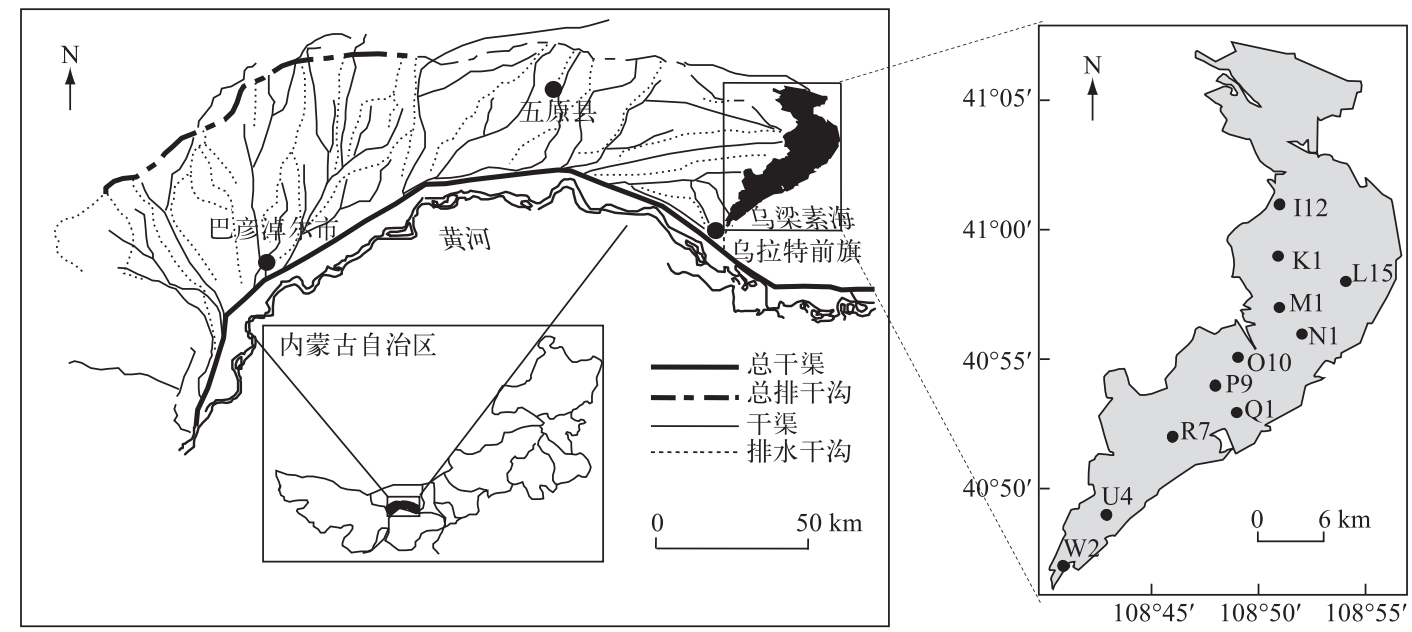

图 1 乌梁素海位置及采样点

Fig.1 Location and sampling sites of Lake Ulansuhai

\section{3 监测方法}

各指标监测方法如表 1 所示.

\section{4 富营养化评价方法}

选用评价结果分辨率较高的分形理论评价模型对乌梁素海结冰前后的富营养化等级进行评价 ${ }^{[7]}$.

1.4.1 单指标分形维数计算 (1) 选用关联维数计算分形维数, 设研究水质指标 $X_{i}$ 的数据向量为: $X_{i}=\left(x_{i 1}\right.$ 、 $\left.x_{i 2} 、 \cdots 、 x_{i n}\right), n$ 为样本数据的总数.

(2) 建立 1 7 维相空间, 运用式 (1) 和式(2) 分别计算每维相空间两点间距离 $r_{p, q}(s)$ 与平均距离 $\Delta x_{s}$ : 
表 1 各指标监测方法

Tab. 1 The methods of each item

\begin{tabular}{cccc}
\hline 指标 & 监测方法 & 标准号 & 精度或检出限 \\
\hline 水深、冰厚 & 钻孔后用尺子直接量取 & - & $1 \mathrm{~cm}$ \\
$\mathrm{SD}$ & 塞氏盘法 & - & $5 \mathrm{~cm}$ \\
$\mathrm{Chl.a}$ & 丙酮萃取分光光度法 & $\mathrm{SL} 88-2012$ & $0.11 \mu \mathrm{g} / \mathrm{L}$ \\
$\mathrm{TN}$ & 过硫酸钾消解紫外分光光度法 & $\mathrm{GB} 11894-1989$ & $0.05 \mathrm{mg} / \mathrm{L}$ \\
$\mathrm{TP}$ & 钿酸铵分光光度法 & $\mathrm{GB} / \mathrm{T} 11893-1989$ & $0.01 \mathrm{mg} / \mathrm{L}$ \\
$\mathrm{COD}$ & 重铬酸钾法 & $\mathrm{GB} 11914-1989$ & $5 \mathrm{mg} / \mathrm{L}$ \\
\hline
\end{tabular}

$$
\begin{aligned}
& r_{p, q}(s)=\sqrt{\sum_{k=1}^{s}\left(x_{p k}-x_{q k}\right)^{2}} \\
& \Delta x_{s}=\sum_{p=1}^{n-s+1} \sum_{q=1}^{n-s+1} \frac{r_{p, q}(s)}{(n-s+1)^{2}}
\end{aligned}
$$

式中, $p, q=1 、 2 、 \cdots 、 n-s+1 ; s=1 、 2 、 \cdots 、 w$ ( $w$ 为最大相空间维数).

(3) 运用式 (3) 和式 (4) 计算每维相空间两点间距离小于 $r_{s k}$ 的概率 $C_{k}(S)$, 从而得到关联积分函数:

$$
\begin{gathered}
C_{k}(S)=\frac{1}{(n-x+1)^{2}} \sum_{p} \sum_{q} H\left(r_{s k}-r_{p, q}(S)\right) \\
H\left(r_{s k}-r_{p, q}(s)\right)=\left\{\begin{array}{l}
1, \text { 当 } r_{s k}-r_{p, q}(s) \geqslant 0 \\
0, \text { 当 } r_{s k}-r_{p, q}(s)<0
\end{array}\right.
\end{gathered}
$$

式中, $r_{s k}$ 为指定的距离上限; $H$ 为 Heaviside 函数; $p, q=1 、 2 、 \cdots 、 n-s+1 ; s=1 、 2 、 \cdots 、 w ; k=1 、 2 、 \cdots 、 14$.

(4) 根据每维相空间求出的一组 $(k=14) C_{k}(s)$ 值, 若 $C_{k}(s)$ 和 $r_{s k}$ 双对数图上为直线, 则分形存在, 其斜率 为分维数:

$$
D_{S}=\lim _{r_{u} \rightarrow 0} \frac{\ln C_{k}(s)}{\ln r_{s k}}
$$

若分维数在相空间维数升高时趋向极限, 此极限即为空间的分维数; 若分维数未严格地趋向极限, 则需 要比较不同相空间的分维数, 选择相邻空间分维数之差满足一定精度或趋于稳定的最大者, 将其作为该水 质指标的分维数.

1.4.2 水质评价指标的分维数 运用上述方法可求出各指标的分维数: (Chl. a, TP, TN, $\left.\mathrm{COD}_{\mathrm{Cr}}, \mathrm{SD}\right)=$ $(0.33,1.17,1.00,1.59,1.83)$, 分维数越大的水质指标越重要.

1.4.3 评价标准的建立 用式 (6) 建立各级别的评价标准:

$$
F_{s}=\sum_{j=1}^{n}(D(i) \cdot S(i))
$$

式中, $F$ 为评价标准 $; i$ 代表第 $i$ 种指标, $i=1 、 2 、 \cdots 、 n ; D(i)$ 和 $S(i)$ 分别为第 $i$ 种指标的分形维数和实测值.

表 2 水质评价标准 ${ }^{[7]}$

Tab.2 The estimation standard of water quality

\begin{tabular}{lccccc}
\hline 水质级别 & $\mathrm{Chl.a} /\left(\mathrm{mg} / \mathrm{m}^{3}\right)$ & $\mathrm{TP} /\left(\mathrm{mg} / \mathrm{m}^{3}\right)$ & $\mathrm{TN} /\left(\mathrm{mg} / \mathrm{m}^{3}\right)$ & $\mathrm{COD}_{\mathrm{rr}} /(\mathrm{mg} / \mathrm{L})$ & $\mathrm{SD} / \mathrm{m}$ \\
\hline 贫营养 & 1 & 2.5 & 30 & 0.3 & 10 \\
贫中营养 & 2 & 5 & 50 & 0.4 & 5 \\
中营养 & 4 & 25 & 300 & 2 & 1.5 \\
中富营养 & 10 & 50 & 500 & 4 & 1 \\
富营养 & 65 & 200 & 2000 & 10 & 0.4 \\
重富营养 & 160 & 600 & 6000 & 25 & 0.3 \\
\hline
\end{tabular}

所建立的评价标准为: (贫营养, 贫中营养, 中营养, 中富营养, 富营养和重富营养 $)=(52.06,66.30$, 
$336.4,569.86,2271.48,6793.32)$.

\section{2 结果与分析}

\section{1 湖泊水深和冰厚的分布}

为了解采样时湖泊各采样点的冰厚和水深等水文特性, 对湖面 11 个采样点的水深、冰厚进行监测分析 (图 2), 结果表明乌梁素海采样期各采样点的水深介于 $0.46 \sim 2.88 \mathrm{~m}$ 之间, 其平均值为 $1.17 \mathrm{~m}$, 相对标准偏 差为 0.54 ; 冰厚介于 $0.32 \sim 0.55 \mathrm{~m}$ 之间, 其平均值为 $0.43 \mathrm{~m}$, 相对标准偏差为 0.17 . 湖泊的南部和北部水深较 深, 中部水深较浅, 而湖泊中部的冰厚较南部和北部大, 这表明冰厚与水深存在较好的负相关性, 其相关系 数为 0.54 (图 3), 这可从热力学对湖冰形成过程的影响进行解释: 整个湖泊处于相同的环境条件下,任意湖 泊区域大气一冰界面的冷通量相等, 水深越浅, 受冷水的体积越小, 冰下水体更易达到过冷状态, 进而使得冰 厚较快增加, 即与水深呈负相关关系.

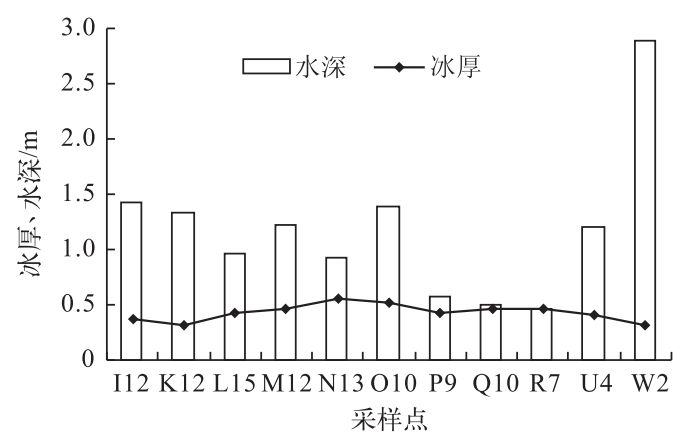

图 2 各采样点冰厚和水深变化

Fig. 2 The variety of ice thickness and water depth of each sampling site

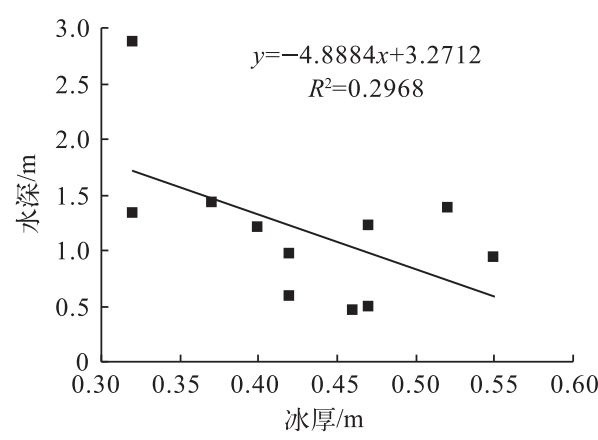

图 3 冰厚与水深关系图

Fig.3 The relationship between ice thickness and water depth

\section{2 湖泊富营养化等级评价}

运用分形理论评价模型对乌梁素海结冰前水体、结冰后冰体融水和冰下水的富营养化等级进行综合评 价(表 3).

结冰前, 乌梁素海湖泊 11 个采样点均达到了富营养化程度, 已经没有贫营养、贫中营养和中营养的区 域出现 (图 4). 这是由于近年来, 河套灌区实施严格的节水灌溉制度, 人湖水量减少, 水位下降, 而化肥施用 量却逐年增加. 据统计, 2009 年河套灌区的化肥施用量已达 $72 \times 10^{4} \mathrm{t}$, 是 1978 年的 10.2 倍,其中大约 $70 \%$ 的 化肥经总排干流人湖内, 并且沿途还汇人了大量的工业废水和生活污水 ${ }^{[8]}$, 致使乌梁素海湖泊水质日益恶 化, 全湖均达到了富营养化程度.

结冰后, 冰下水样中, 5 个采样点达到了重富营养化程度, 占样品数量的 $45.4 \%, 6$ 个采样点仍然富营养 化, 占样品数量的 $54.6 \%$, 全湖均值的评价结果为 3738.29 , 评价等级为重富营养; 冰层融水样品中, 7 个采样 点为中富营养, 占样品数量的 $63.6 \%, 4$ 个采样点为富营养化, 占样品数量的 $36.4 \%$, 全湖均值的评价等级为 富营养,但其评价结果为 877.14 , 仅为冰前水评价结果的 $54.6 \%$ (表 3).

\section{3 结冰对富营养化状态的影响}

从全湖分形评价均值来看, 结冰前后, 湖泊水体的富营养化等级由富营养变为重富营养, 这表明结冰过 程加剧了水体的富营养化程度, 结冰过程中, 氮、磷等营养元素被排斥至冰下水体, 即结冰过程对营养元素 具有浓缩效应.

湖泊结冰过程的浓缩效应可从湖冰的形成过程进行解释: 湖冰的形成是一个从敞开水域到部分水域, 最后到全水域冰覆盖的过程. 当气温低于 $0^{\circ} \mathrm{C}$ 时, 湖泊表层达到过冷状态, 形成自发长大的冰核. 随着负温度 的累积, 湖面上形成细小、平整且不含杂质的片状冰晶, 这些冰晶多平卧水面, 在生长过程逐渐生长为更加 
表 3 实测数据和评价结果

Tab.3 Original data and estimating results

\begin{tabular}{|c|c|c|c|c|c|c|c|c|c|}
\hline & \multicolumn{3}{|c|}{ I12 } & \multicolumn{3}{|c|}{ K12 } & \multicolumn{3}{|c|}{ L15 } \\
\hline & 冰前水 & 冰融水 & 冰下水 & 冰前水 & 冰融水 & 冰下水 & 冰前水 & 冰融水 & 冰下水 \\
\hline Chl.a/ $\left(\mathrm{mg} / \mathrm{m}^{3}\right)$ & 66.33 & 95.48 & 120.40 & 102.41 & 85.43 & 140.30 & 33.17 & 30.15 & 50.25 \\
\hline $\mathrm{TP} /\left(\mathrm{mg} / \mathrm{m}^{3}\right)$ & 140 & 180 & 280 & 100 & 440 & 670 & 100 & 70 & 110 \\
\hline $\mathrm{TN} /\left(\mathrm{mg} / \mathrm{m}^{3}\right)$ & 830 & 900 & 3200 & 880 & 1169 & 4010 & 660 & 463 & 1500 \\
\hline $\mathrm{COD}_{\mathrm{Cr}} /(\mathrm{mg} / \mathrm{L})$ & 72.22 & 43.13 & 122.37 & 154.46 & 132.40 & 311.94 & 149.45 & 118.35 & 305.92 \\
\hline $\mathrm{SD} / \mathrm{m}$ & 0.62 & 5.80 & 0.70 & 0.89 & 5.50 & 0.85 & 1.20 & 6.50 & 1.00 \\
\hline 评价结果 & 1131.65 & 1221.30 & 3763.18 & 1278.02 & 1932.56 & 5337.74 & 1027.76 & 754.93 & 2133.28 \\
\hline \multirow[t]{3}{*}{ 评价级别 } & 富营养 & 富营养 & 重富营养 & 富营养 & 富营养 & 重富营养 & 富营养 & 富营养 & 富营养 \\
\hline & \multicolumn{3}{|c|}{ M12 } & \multicolumn{3}{|c|}{ N13 } & \multicolumn{3}{|c|}{010} \\
\hline & 冰前水 & 冰融水 & 冰下水 & 冰前水 & 冰融水 & 冰下水 & 冰前水 & 冰融水 & 冰下水 \\
\hline Chl.a/ $\left(\mathrm{mg} / \mathrm{m}^{3}\right)$ & 27.14 & 28.14 & 45.23 & 27.14 & 24.12 & 42.21 & 9.05 & 7.04 & 10.05 \\
\hline $\mathrm{TP} /\left(\mathrm{mg} / \mathrm{m}^{3}\right)$ & 80 & 210 & 380 & 120 & 150 & 210 & 210 & 150 & 250 \\
\hline $\mathrm{TN} /\left(\mathrm{mg} / \mathrm{m}^{3}\right)$ & 600 & 469 & 1420 & 260 & 238 & 1190 & 350 & 88 & 270 \\
\hline $\mathrm{COD}_{\mathrm{Cr}} /(\mathrm{mg} / \mathrm{L})$ & 122.37 & 70.21 & 213.64 & 108.32 & 62.19 & 195.59 & 105.32 & 31.09 & 98.29 \\
\hline $\mathrm{SD} / \mathrm{m}$ & 1.00 & 6.00 & 1.20 & 0.90 & 6.50 & 0.70 & 1.00 & 6.20 & 0.80 \\
\hline 评价结果 & 898.95 & 846.60 & 2221.16 & 583.24 & 520.53 & 1761.66 & 767.97 & 326.61 & 723.57 \\
\hline \multirow[t]{3}{*}{ 评价级别 } & 富营养 & 富营养 & 富营养 & 富营养 & 中富营养 & 富营养 & 富营养 & 中富营养 & 富营养 \\
\hline & \multicolumn{3}{|c|}{ P9 } & \multicolumn{3}{|c|}{ Q10 } & \multicolumn{3}{|c|}{ R7 } \\
\hline & 冰前水 & 冰融水 & 冰下水 & 冰前水 & 冰融水 & 冰下水 & 冰前水 & 冰融水 & 冰下水 \\
\hline Chl.a/ $\left(\mathrm{mg} / \mathrm{m}^{3}\right)$ & 23.12 & 25.13 & 40.20 & 27.14 & 35.18 & 42.21 & 30.15 & 18.09 & 26.13 \\
\hline $\mathrm{TP} /\left(\mathrm{mg} / \mathrm{m}^{3}\right)$ & 80 & 40 & 90 & 70 & 30 & 90 & 60 & 100 & 160 \\
\hline $\mathrm{TN} /\left(\mathrm{mg} / \mathrm{m}^{3}\right)$ & 290 & 325 & 1020 & 3060 & 313 & 5030 & 3470 & 175 & 5530 \\
\hline $\mathrm{COD}_{\mathrm{Cr}} /(\mathrm{mg} / \mathrm{L})$ & 154.46 & 78.23 & 271.82 & 150.45 & 108.32 & 325.98 & 77.23 & 41.12 & 127.38 \\
\hline $\mathrm{SD} / \mathrm{m}$ & 0.80 & 5.60 & 0.90 & 0.40 & 5.20 & 0.50 & 0.50 & 4.80 & 0.50 \\
\hline 评价结果 & 638.29 & 514.73 & 1572.16 & 3390.80 & 541.46 & 5668.21 & 3673.86 & 372.14 & 5929.27 \\
\hline \multirow[t]{3}{*}{ 评价级别 } & 富营养 & 中富营养 & 富营养 & 重富营养 & 中富营养 & 重富营养 & 重富营养 & 中富营养 & 重富营养 \\
\hline & \multicolumn{3}{|c|}{$\mathrm{U} 4$} & \multicolumn{3}{|c|}{$\mathrm{W} 2$} & \multicolumn{3}{|c|}{ 平均值 } \\
\hline & 冰前水 & 冰融水 & 冰下水 & 冰前水 & 冰融水 & 冰下水 & 冰前水 & 冰融水 & 冰下水 \\
\hline Chl.a/ $\left(\mathrm{mg} / \mathrm{m}^{3}\right)$ & 44.22 & 17.09 & 25.13 & 77.39 & 58.29 & 86.43 & 69.35 & 44.22 & 108.54 \\
\hline $\mathrm{TP} /\left(\mathrm{mg} / \mathrm{m}^{3}\right)$ & 60 & 140 & 270 & 100 & 90 & 210 & 101 & 124 & 322 \\
\hline $\mathrm{TN} /\left(\mathrm{mg} / \mathrm{m}^{3}\right)$ & 710 & 175 & 520 & 1440 & 391 & 2250 & 1242 & 600 & 2908 \\
\hline $\mathrm{COD}_{\mathrm{Cr}} /(\mathrm{mg} / \mathrm{L})$ & 54.16 & 40.12 & 101.30 & 121.36 & 69.17 & 224.68 & 140.42 & 67.20 & 261.78 \\
\hline $\mathrm{SD} / \mathrm{m}$ & 1.00 & 5.40 & 0.70 & 1.50 & 6.20 & 1.20 & 0.88 & 5.80 & 0.82 \\
\hline 评价结果 & 882.74 & 418.11 & 1006.54 & 1778.25 & 525.98 & 2883.41 & 1607.93 & 877.14 & 3738.29 \\
\hline 评价级别 & 富营养 & 中富营养 & 富营养 & 富营养 & 中富营养 & 重富营养 & 富营养 & 富营养 & 重富营养 \\
\hline
\end{tabular}

利于释放潜热的星形或树枝形, 这些冰晶相互连接便可形成柔性冰, 柔性冰经冻结变厚, 形成坚硬冰盖, 并 形成冰-水界面. 由于冰盖的形成, 使得冷能通过冰盖稳定的传递, 而由于氮、磷等污染物的凝固点较低, 冷 能仅能够使得在冰一水界面处的水分子达到凝固点而平稳析出, 且晶核生长的速度大于其形成的速度 ${ }^{[9]}$, 随 着晶核的长大,其将附着在冰盖的下表面上形成洁净冰体,而氮、磷等营养元素则被排斥至冰下水体. 但当 温度较低时, 冰晶体的形成速率加快, 在冰的快速生长过程中会有部分杂质不能被及时排斥至冰下水体, 而 被俘获在纯净的冰体之间 (图 5). 氮、磷等杂质被俘获的过程与海冰形成过程中盐的俘获相似,且该俘获过 程与冰生长速率、冰体结构、冰下水环流和水体中杂质的含量等因素相关 ${ }^{[10]}$. 特别是气温骤降时, 冰的生长 


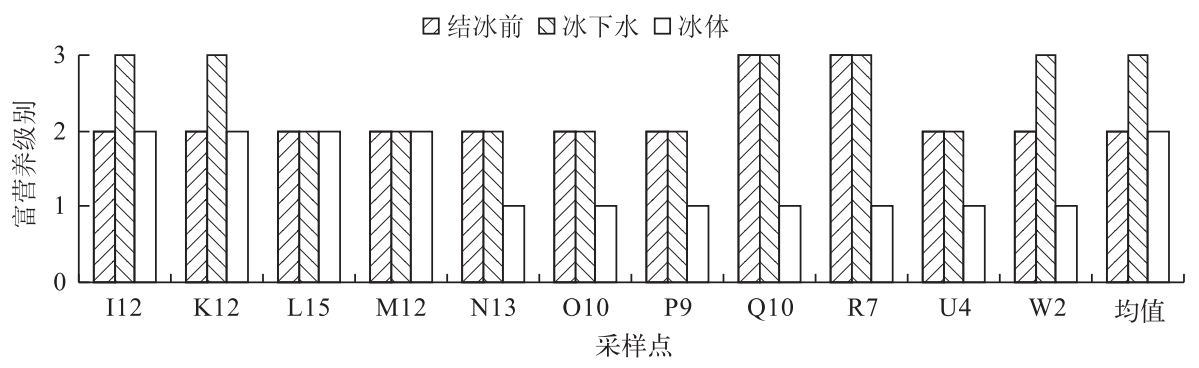

图 4 结冰前水体、冰融水和冰下水体的富营养化等级 (1-中富营养;2-富营养;3-重富营养)

Fig.4 The eutrophic state of water before icing, ice meltwater and under-ice water

速率骤增, 将会有更多的杂质被俘获在冰体中 ${ }^{[11-12]}$, 但仍有部分杂质被排斥至冰下水体, 使得冰下水体中 氮、磷等污染物浓度仍高于冰体.

从热力学角度来看, 由于水和氮、磷等污染物物理性质的不同, 随着气温的降低, 整个体系的温度也将 下降, 使水分子对氮、磷等污染物分子的溶剂化作用减弱, 水分子在氢键作用下首先缔结析出, 形成纯净冰 体, 而氮、磷等污染物分子被排斥至冰下水体中. 但在湖冰形成初期和气温骤降时, 由于氮、磷等污染物的溶 解度降低,会有部分污染物会从饱和或过饱和的溶液中析出, 并可能形成临界尺寸的冰核, 促使水溶液异相 成核 ${ }^{[13-14]}$, 即部分污染物被冻结在冰体中,但其在冰体中的浓度仍然小于冰下水体.

从固液平衡理论分析 (图 6), 曲线 $\mathrm{ABDE}$ 是湖水的冰点线. $\mathrm{A}$ 点是纯水的冰点, 但在一定范围内湖水的 冰点会随着污染物浓度的增加而有所降低. 随着气温的逐渐降低, 湖水温度将由 $\mathrm{T}_{0}$ 降至 $\mathrm{T}_{1}$, 湖水达到过冷状 态即开始结冰, 气温继续降低至 $\mathrm{T}_{2}$ 时, 洁净冰晶形成、生长并从水体中分离出来, 此时湖水污染物浓度由 $\mathrm{C}_{0}$ 增加至 $\mathrm{C}_{1} . \mathrm{E}$ 点为共晶点, $\mathrm{T}_{3}$ 为共晶点温度, 气温继续降低时, 水分子以洁净冰晶的形式从冰下水体中不断 析出, 而氮、磷等污染物分子被排斥至冰下水体中, 随着冰层厚度的增加, 水体中氮、磷等污染物会达到饱 和, 甚至从水体中析出 ${ }^{[15]}$.

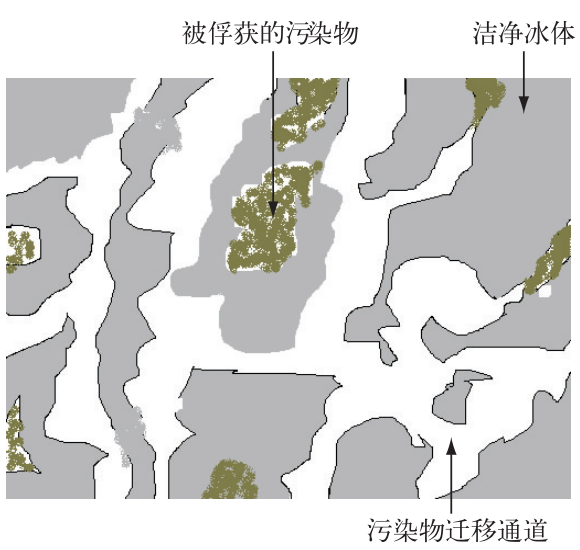

图 5 冰结构剖面示意图

Fig.5 Schematic diagram of ice structure

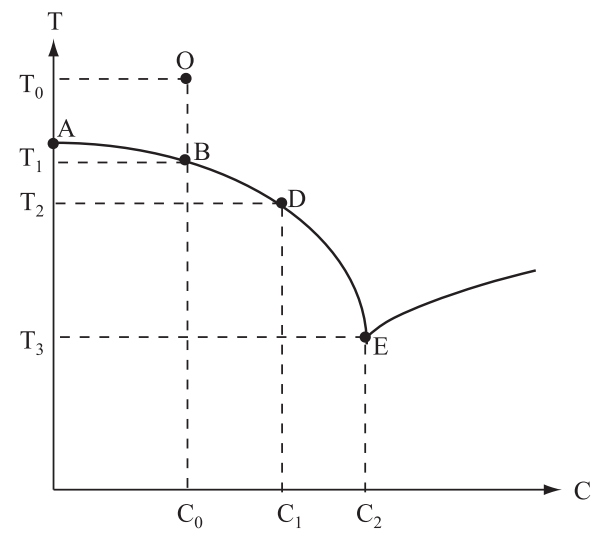

图 6 温度-浓度平衡曲线

Fig.6 Temperature-concentration balance curve

尽管湖泊冰封期冰下水体氮、磷等营养元素已超过富营养化发生的临界浓度, 但冰下水体的温度一直 稳定在 $0^{\circ} \mathrm{C}$ 附近, 抑制了藻类增殖, 同时由于冰层的覆盖减弱了冰下水体的光照强度, 削弱了水体流速, 扰动 等水动力条件 ${ }^{[16]}$,一般不会出现藻类异常增殖的情况 ${ }^{[17]}$. 但根据 Langmuir 吸附理论可知, 冰下水体氮、磷等 浓度的升高, 会打破水-沉积物之间存在着的氮、磷等的浓度平衡, 使得氮、磷等污染物在物理、化学和生物 的耦合作用下由水体向沉积物迁移 ${ }^{[5]}$, 成为新的内源污染, 也有研究指出, 与非冰封期相比, 低温和冰下水 
的低扰动都将加快污染物向沉积物的迁移 ${ }^{[18-19]}$, 而该过程使得冰-水体系中氮、磷等的总量减少, 这在一定 程度上可以缓解因冷冻浓缩而引起的冰下水体的重富营养状态. 但是, 冰体融化后, 水体中氮、磷等污染物 的浓度迅速下降, 打破沉积物一水两相界面的物质平衡, 在风力以及其他外力的扰动下, 大量聚集在沉积物 中的污染物会重新悬浮而再次进人湖泊水体中 ${ }^{[20]}$. 另外, 对部分作为饮用水水源的湖泊而言, 结冰过程使 得冰下水体中氮、磷等污染物浓度升高, 加之给水厂在冬季的处理效率降低, 使得生活饮用水的水质下降, 甚至难以达到生活饮用水卫生标准( GB 5749-2006) 的要求.

\section{4 浅水湖泊冰封期富营养化污染治理建议}

由前述可知, 结冰过程对湖泊水体中氮、磷等污染物具有浓缩效应, 使冰下水体中污染物浓度增加, 进 而使得冰下水体中的污染物向沉积物迁移, 并且冰厚与水深存在较好的负相关性, 因此, 可从湖泊冰封期富 营养化特征的特殊性人手, 提出湖泊特别是浅水湖泊冰封期富营养化的治理建议.

底泥疏浚是治理湖泊内源污染的有效措施之一,但由于疏浚过程属于水上作业,耗资巨大 ${ }^{[21]}$. 而在浅 水湖泊冰封期, 可以进行冰上作业, 从而降低工程成本, 可使底泥疏浚工程得以大规模推广. 此外, 湖泊冰封 期水体中的污染物向沉积物迁移,致使沉积物中污染物浓度提高,因此可以提高底泥疏浚效果.

由于湖泊冰封期冰体较为洁净, 可采用冰体和水体分离的方法, 移出并净化浅水湖泊冰下较小体积的 浓缩液, 必要时可将冰下水体多次冻结, 获得更小体积和更高浓度的冰下浓缩液 ${ }^{[22]}$, 由此可以移除大量污染 物. 待气温回升后, 洁净冰体将自然融化形成低浓度的冰融水. 但是该方法会威胁水生生物群落, 破坏水生 态系统的物质循环和能量流动过程, 降低水体的自净能力, 如能取得突破, 可为湖泊富营养化污染提供一种 经济与效益并优的治理方法.

\section{3 结论}

1) 湖泊的结冰厚度与湖水深度具有良好的负相关性,即湖水越深,冰层厚度越小.

2) 结冰过程对氮、磷等营养元素具有浓缩效应, 乌梁素海结冰后, 水体的富营养化等级由富营养变为重 富营养,即结冰过程加剧了水体的富营养化程度,并会对冰下水环境质量带来不良影响.

3) 利用结冰过程的浓缩效应,理论上可通过底泥疏浚和冰水分离的方式对富营养湖泊进行治理,但在 实际工程中可能存在破坏水体生态系统等缺点, 需为其开展深人研究.

致谢: 感谢内蒙古农业大学 “河、湖、湿地水环境保护与修复技术研究团队” 的同学在野外采样工作中给予 的无私帮助.

\section{4 参考文献}

[ 1 ] Yang Guishan, Ma Ronghua, Zhang Lu et al. Lake status, major problems and protection strategy in China. J Lake Sci, 2010, 22(6) : 799-810. DOI: 10.18307/2010.0601. [杨桂山, 马荣华, 张路等. 中国湖泊现状及面临的重大问题与 保护策略. 湖泊科学, 2010, 22(6): 799-810.]

[ 2 ] Huang Jiguo, Peng Xiangie, Yu Shuang et al. Distribution characteristics of nutrient and chlorophyll a during the icebound season. Journal of Jilin University: Science Edition, 2008, 46(6): 1231-1236. [黄继国, 彭祥捷, 俞双等. 水体 结冰期营养盐和叶绿素 a 的分布特征. 吉林大学学报: 理学版, 2008, 46(6) : 1231-1236.]

[ 3 ] Huang Jiguo, Fu Xinting, Wang Xuesong et al. The distribution characteristics of nutrients and phytoplankton during the icebound season in Changchun. Acta Scientiae Circumstantiae, 2009, 20(8) : 1678-1683. [黄继国, 傅金廷, 王雪松等. 湖水冰封期营养盐及浮游植物的分布特征. 环境科学学报, 2009, 20(8): 1678-1683.]

[ 4 ] Jiang Huiqin. Experimental study on the spatial distribution of nutrient salts in the ice of lake wuliangsuhai and their release processes during melting [Dissertation]. Huhhot: Inner Mongolia Agricultural University, 2011. [姜慧琴. 乌梁素海 营养盐在冰体中的空间分布及其在冻融过程中释放规律的试验研究 [ 学位论文]. 呼和浩特: 内蒙古农业大 学, 2011.]

[ 5 ] Zhang Yan, Li Changyou, Shen Hungtao et al. Total nitrogen migration in Wuliangsuhai Lake during ice growth process. Advances in Water Science, 2013, (5) : 728-735. [张岩, 李畅游, Shen Hungtao 等. 乌梁素海湖泊冰生长过程中总氮 的迁移规律. 水科学进展, 2013, (5): 728-735. ] 
[ 6 ] Huang Wenfeng. Study on lake ice microstructure and its effects on thermal and mechanical parameters[Dissertation]. Dalian: Dalian University of Technology, 2013. [黄文峰. 湖冰微结构及其及其对冰热、力学参数影响的研究 [ 学位论 文]. 大连: 大连理工大学, 2013.]

[ 7 ] Liu Guangping, Du Ping, Wang Kun. Application of fractal theory to evaluation of lake eutrophication. Acta Agriculturae Universitatis Jiangxiensis, 2005, 27(6): 925-929. [刘光萍, 杜萍, 王琨. 分形理论在湖泊富营养化评价中的应用. 江西农业大学学报, 2005, 27(6): 925-929.]

[ 8 ] Zhan Yong, Li Changyou, Shi Xiaohong et al. Application of fractal theory to the evaluation of water quality in Wuliangsuhai Lake. Journal of Water Resource and Water Engineering, 2012, 23(2): 37-43. [詹勇, 李畅游, 史小红等. 分形理 论在乌梁素海湖泊水质评价中的应用. 水资源与水工程学报, 2012, 23(2): 37-43.]

[ 9 ] Guillaume G, Olivier L, Aza A et al. Wastewater treatment by radial freezing with stirring effects. Water Research, 2003, 37: 2520-2524. DOI: 10.1016/S0043-1354(03)00020-4.

[10] Weeks WF, Ackley SF. The growth, structure and properties of sea ice. New York: Plenum Press, 1989: 9-164.

[11] Weeks WF, Lee OS. Observation on the physical properties of sea ice at Hopedale, Labrador. Arctic, 1958, 11(3): 135-155.

[12] Nakawo M, Sinha NK. Growth rate and salinity profile of first-sea ice in the high Arctic. Journal of Glaciology, 1981, 27 (96) : 315-330.

[13] Gao W, Smith DW, Sego DC. Ice nucleation in industrial wastewater. Cold Regions Science and Technology, 1999, 29: 121-133. DOI: 10.1016/S0165-232X(99)00019-1.

[14] Song Meifeng, Liu Daoping, Wu Zhimin et al. Study on nucleation and growth mechanism of snow crystal. Journal of Refrigeration, 2004, 25(3): 46-50. [ 宋玫峰, 刘道平, 邬志敏等. 雪晶成核和生长机理研究. 制冷学报, 2004,25 (3) : 46-50.]

[15] Olivier L, Pascal T, Eugenie B et al. Potential of freezing in wastewater treatment: Soluble pollutant application. Water Research, 2001, 35(2) : 541-547. DOI: 10.1016/S0043-1354(00) 00287-6.

[16] Iversen KR, Primicerio R, Larsen A et al. Effects of small-scale turbulence on lower trophic levels under different nutrient conditions. Journal of Plankton Research, 2010, 32(2) : 197-208.

[17] Pennak RW. Field and experimental winter limnology of three Colorado mountain lakes. Ecology, 1968, 49(3) : 505-520.

[18] Belzile C, Gibson JAE, Vincent WF. Colored dissolved organic matter and dissolved organic carbon exclusion from lake ice: Implication for irradiance transmission and carbon cycling. Limnology and Oceanography, 2002, 47( 5 ) : 1283-1293. DOI : $10.4319 /$ lo.2002.47.5.1283.

[19] He Jiang, Sun Ying, Lü Changwei et al. Research on phosphorus release from the surface sediments in the Daihai Lake. Acta Ecologica Sinica, 2010, 30(2) : 389-398. [何江, 孙英, 吕昌伟等. 岱海表层沉积物中内源磷的释放. 生态学 报, 2010, 30(2): 389-398.]

[20] Petterson K. Mechanisms for internal loading of phosphorus in lakes. Hydrobiologia, 1998, 373/374: 21-25.

[21] Zhong Jicheng, Fan Chengxin. Advance in the study on the effectiveness and environmental impact of sediment dredging. $J$ Lake Sci, 2007, 19(1) : 1-10. DOI: 10.18307/2007.0101. [ 钟继承, 范成新. 底泥疏浚效果及环境效应研究进展. 湖 泊科学, $2007,19(1): 1-10$.]

[22] Gao W, Habib M, Smith DW. Removal of organic contaminants and toxicity from industrial effluents using freeing processes. Desalination, 2009, 245(1): 108-119. 